\title{
The Effectiveness of the Gesture-Based Learning System (GBLS) and Its Impact on Learning Experience
}

\author{
Moamer Shakroum, Kok Wai Wong, and Lance Chun Che Fung \\ Murdoch University, Murdoch, WA, Australia \\ M.Shakroum@Murdoch.edu.au; K.Wong@Murdoch.edu.au; , \\ L.Fung@murdoch.edu.au
}

\begin{abstract}
Several studies and experiments have been conducted in recent years to examine the value and the advantage of using the Gesture-Based Learning System (GBLS). The investigation of the influence of the GBLS mode on the learning outcomes is still scarce. Most previous studies did not address more than one category of learning outcomes (cognitive, affective outcomes, etc.) at the same time when used to understand the impact of GBLS. Moreover, none of these studies considered the difference in students' characteristics such as learning styles and spatial abilities. Therefore, a comprehensive empirical research on the impact of the GBLS mode on learning outcomes is needed. The purpose of this paper is to fill in the gap and to investigate the effectiveness of the GBLS mode on learning using Technology Mediated Learning (TML) models. This study revealed that the GBLS mode has greater positive impact on students' learning outcomes (cognitive and affective outcomes) when compared with other two learning modes that are classified as Computer Simulation Software Learning (CSSL) mode and conventional learning mode. In addition, this study also found that the GBLS mode is capable of serving all students with different learning styles and spatial ability levels. The results of this study revealed that the GBLS mode outperformed the existing learning methods by providing a unique learning experience that considers the differences between students. The results have also shown that the Kinect user interface can create an interactive and an enjoyable learning experience.
\end{abstract}

Keywords: Gesture Based Learning System (GBLS), Computer Simulated Software Learning (CSSL) mode, Kinect sensor, Perceptual User Interface (PUI), learning technology, Technology Mediated Learning (TML), Learning Outcomes.

\section{Introduction}

For many years, ICT has been used as a supporting tool in the education field. In the modern

Material published as part of this publication, either on-line or in print, is copyrighted by the Informing Science Institute. Permission to make digital or paper copy of part or all of these works for personal or classroom use is granted without fee provided that the copies are not made or distributed for profit or commercial advantage AND that copies 1) bear this notice in full and 2) give the full citation on the first page. It is permissible to abstract these works so long as credit is given. To copy in all other cases or to republish or to post on a server or to redistribute to lists requires specific permission and payment of a fee. Contact Publisher@InformingScience.org to request redistribution permission. education era, computers have become an essential component of any classroom. Despite the fact that ICT technologies can bring several benefits to the learning processes, there is always a fear of overestimating the abilities of the emerging technologies (Abrahamson, Gutiérrez, Charoenying, Negrete, \& Bumbacher, 2012; Cuban, 1986; Watson, 2001). According to John and 
Sutherland (2005), ICT technology should be evaluated carefully before making a decision of adopting it in the education field. They emphasised that the ICT evaluation should include testing the technology in relation to the pedagogy within the subject area. In addition, the technology should also be evaluated in respect to the teaching method in the culture of the topic domain.

Several studies have shown that the Gesture-Based Learning System (GBLS) mode has a positive effect on students' performance and created an enjoyable and interactive learning environment (Di Tore, 2012; Sheu \& Chen, 2014). According to Sheu, Fang, and Chen (2013), the GBLS's research field is still at its infancy stage; more studies are needed in order to determine the potential of the GBLS mode. A comprehensive scientific study that investigates the effectiveness of the GBLS mode can help to draw the lines of the efficacy and the future use of the GBLS mode. The aim of this study is to investigate the impact of the GBLS mode on the learning outcomes, as well as investigating whether the GBLS mode is able to accommodate all learners with different learning styles and spatial abilities. Such a study can provide scientific results that can be used to judge the potential of the GBLS mode in the education sector. This study addressed the following research questions:

- Does the GBLS mode positively influence the students' learning outcomes?

- Will the GBLS mode be able to accommodate all students with different learning styles and spatial abilities?

\section{Literature Review}

This section provides the basic knowledge of different related discipline areas such as learning interfaces' technologies, Technology Mediated Learning (TML), and learning theories. This section is divided into four sub-sections as follows. Firstly, the Perceptual User Interface (PUI) will be described. Secondly, a brief description of the technical aspects of the Kinect sensor that is the user interface used. Thirdly, the main topic of the GBLS mode will be described, and the benefits and the potential of the GBLS mode will be highlighted. Finally, the explanation of the theoretical background of the topic and the reviewing of the previous work will be presented. Systematic literature review method was used to perform the literature review.

\section{Perceptual User Interface (PUI)}

In the last decade, Human-Computer Interface (HCI) specialists started to discuss the post-WIMP metaphor (Turk, 2001). WIMP is referring to Windows, Icons, Menus, and Pointing devices such as mouse and keyboard. The post-WIMP metaphor is Perceptual User Interface (PUI). Examples of the PUI include multimodal interfaces, Virtual Reality, Tangible interface, and Augmented Reality. The idea behind PUI is to utilise the available advanced technologies such as gesture and voice recognition in order to create an intelligent user interface that is capable of understanding the human's natural actions (Oviatt \& Wahlster, 1997; Turk, 2001). According to Turk (2001), the idea of the PUI is to build an interface that translates user semantics to the application semantics using input modes and translates the application semantics to the users semantics using output modes. In other words, PUI aims to add human-perceptual capabilities to the computers in order to recognise the human motions and voices (Turk \& Robertson, 2000). Recently, the Kinect sensor gives a good example of the PUI technologies. As the Kinect sensor is the main focus of this research, it is important to give a brief description of the technical features of the Kinect.

\section{Kinect Sensor}

The Kinect sensor was released in November 2010 by Microsoft as a part of Xbox 360 game console that exemplifies the first controller-free video game console, it was advertised with the slogan "you are the controller" (Lang, Block-Berlitz, \& Rojas, 2011). Microsoft Xbox 360 be- 
came popular in a short period of time, for example, in the first ten days after its release more than 1 million units were sold. Another study reported that, just after 60 days of its release, more than 8 million units of Microsoft Xbox 360 were sold (O'Donovan et al., 2012). The Kinect sensor can be technically described as an RGB camera along with a microphone array and depth sensor using an infrared projector (see Figure 1). The Kinect is able to recognise a player's body movements and voice.
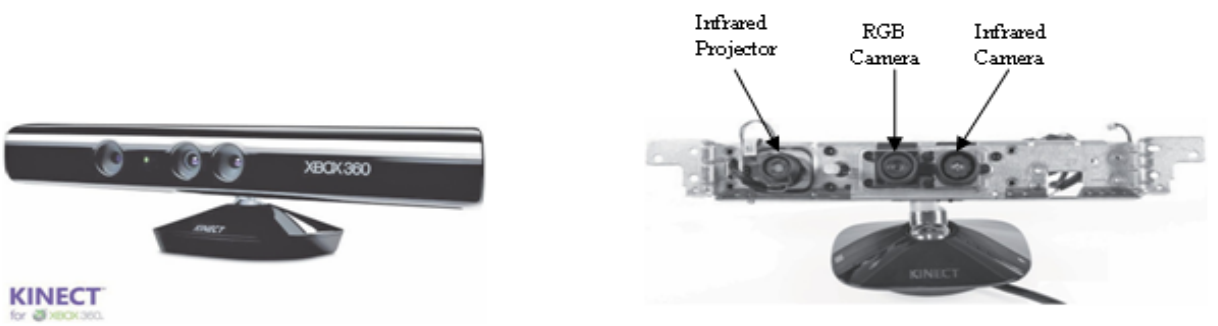

Figure 1: Kinect design (Zhang, 2012)

Shortly after the Kinect's release, a company called Adafruit Industries offered USD 1000 for anybody who could release a complete open-source driver for the Kinect sensor (Villaroman, Rowe, \& Swan, 2011). Not long after that, a hacker successfully developed the first open source Kinect driver called Libfreenect that enable the Kinect to run on Linux. Microsoft responded to this hacking by announcing that the hacker will not be sued for that. In December 2010, PrimeSense released another open-source driver for the Kinect called OpenNI (Hsu, 2011b).In June 2011, Microsoft launched an official non-commercial driver for the Kinect for Windows OS; Microsoft released two versions of Software Developing Kit (SDK), one for personal use and the other one for developers. All the above Kinect drivers used a skeletal tracking model. Those drivers enabled the Kinect sensor to be attached to any PC. Having such a popular device working on the computer has grabbed the attention of learning technologies' researchers and they started looking for the potential of using the Kinect in the education field (Hsu, 2011b; Kam, Konrad, \& Ishwar, 2012; Lang et al., 2011). The scope of using the Kinect in education is described in detail in the following section.

\section{Gesture-Based Learning System (GBLS)}

Using the Kinect in learning has been introduced under different terms such as Kinect in education, natural user interface, gestural interfaces in learning, and Kinect-facilitated learning (Chao, Huang, Fang, \& Chen, 2013; Evans, 2012; Hsu, 2011b). However, in this paper the authors suggested to use a more generic term such as the GBLS mode to represent the use of the Kinect sensor along with a Kinect-based learning application as a teaching and learning tool. The GBLS mode employs the natural user interfaces of the Kinect to create an enjoyable and an interactive learning environment in any formal classrooms (Hsu, 2011a, 2011b; Johnson et al., 2012).

Horizon's reports in 2011 and 2012 listed gesture-based systems as one the emerging technologies that have a great potential to be adopted in the education field within 4 to 5 years (Johnson et al., 2011, 2012). Consequently, the researchers and education specialists were encouraged to take a closer step towards gesture-based systems and to investigate their potential in the education field. Gesture-based systems have also achieved a novel success in gaming and entertainment sectors, which subsequently drew the attention of the researchers in the educational fields (Sheu $\&$ Chen, 2014). In recent years, a number of empirical studies have been conducted to develop and test GBLS. GBLS has been used in different educational disciplines including physics, mathematics, music and arts, science, social development, and physical therapy (Sheu \& Chen, 2014). In addition, some research studied the effect of GBLS on specific learning aspects such memory 
and physical rehabilitation (Chao et al., 2013; Shih-Ching et al., 2012). On the software development side, some projects have been launched to develop GBLS such as KinectEDucation (http://www.kinecteducation.com). KinectEDucation is a non-commercial platform for all GBLS stakeholders including teachers, students, enthusiasts, and software developers (Kandroudi \& Bratitsis, 2012). According to Hsu (2011b), GBLS has a great potential to be the focal learning technology in the classrooms in the near future. In order to understand the advantages of GBLS, it is essential to describe the benefits of GBLS using learning theories. Therefore, the following section was written to link the technological aspects of the GBLS mode to some relevant educational theories.

\section{Theoretical Background and Related Work}

The GBLS mode has started to gain much attention to be one of the promising learning technologies (Johnson et al., 2011, 2012). GBLS can bring several advantages to the classroom as they provide a unique natural interaction method with the teaching material (Evans, 2012). As a result of reviewing the literature on gesture-based systems, it has been found that the Kinect has several features that make it suitable to be used in the education field (Hsu, 2011a, 2011b). However, this section will highlight the GBLS mode's traits and link them to some learning theories. First, the GBLS mode can operate as a stimulating tool for learners that could help to boost their motivation as the GBLS utilises a unique and natural interaction method. Second, the GBLS is a multimodal system and able to facilitate kinaesthetic interactions and coordinate them with auditory and visual information. The coordination of those three different inputs-modalities makes the GBLS mode an excellent learning mode that supports students with various learning styles, especially Kinaesthetic learners (Hsu, 2011a, 2011b). In order to illustrate this, learning style theories argue that students learn through different learning modalities. "Learning modalities are the sensory channels or pathways through which individuals give, receive, and store information. Perception, memory, and sensation comprise the concept of modality" (Gage, 1995). Mainly, there are three learning modalities: auditory, visual, and kinaesthetic. Kinaesthetic learners represent $15 \%$ of the total population of students (Gage, 1995; Hsu, 2011b). Kinaesthetic students learn better when they are physically involved with learning material. According to Gage (1995), kinaesthetic learners have been ignored by most learning methods. However, the GBLS mode will provide kinaesthetic learners with their needs to achieve better performance and at the same time support other learning styles (Hsu, 2011a).

Third is relating to fitness and physical development, besides its value in learning. A study by O'Hanlon (2007) showed that the GBLS mode can help overweight students by engaging them in physical activities during class time. In addition, students will also be forced to be active at home as they have to do their homework. Forth, the GBLS mode supports embodied cognition theory, which argues that students learn better when they combine cognitive tasks with physical movements (Chang, Chien, Chiang, Lin, \& Lai, 2013). Embodied cognition theory suggests that manipulating and interacting with tools change the way we think and comprehend, and this change affects the way we perceive our environment. In other words, embodied cognition theory states that people learn with their bodies to complement their brains (Kirsh, 2013). Several studies have emphasised the positive impact of the combination of physical gestures with cognitive tasks on learning (Ratner, Foley, \& McCaskill, 2001; Stevanoni \& Salmon, 2005). According to Chao et al. (2013), performing physical movement and touching relevant things during learning tasks provide a meaningful learning experience. Fifth, the Kinect is relatively cheap comparing with other learning technologies and can be attached to the classroom computer without the need for installing any other infrastructures. For instance, comparing the price of the Kinect with Interactive Whiteboard (IWB), IWB costs between 800 to 2500 US dollars, while the Kinect only cost 149 US dollars (Hsu, 2011b). 
Chang et al. (2013) ran an experiment using the Kinect as gestural-based multimedia to test the effect of body movements and gestures on learning. The results showed better concept understanding and knowledge retention using Kinect-based learning, the results were measured by pretest and post-test. Moreover, Chao et al. (2013) examined the effect of using gestures during learning on students' memory performance by comparing desktop learning system with the Kinect-enhanced learning method. The results showed that students who used the Kinect recall more information than students who used desktop systems. In addition, Meng et al. (2013) used a Kinect-based learning system to teach anatomy; the results of this research showed that using the Kinect-based learning method outperformed the existing learning system, which was AR magic mirror. AR magic mirror is a medical education technology that creates an illusion, which augments virtual anatomy information to the user who is standing in front of a mirror. Another study (W.-J. Lee, Huang, Wu, Huang, \& Chen, 2012) compared Digital Learning Playground (DLP) with Kinect-enhanced DLP in order to test the effect of embodied interaction on learning performance. The results of this comparison showed that the Kinect-enhanced DLP kept the participants attention on learning and gave them a more enjoyable learning experience than the conventional DLP. Ayala, Mendívil, Salinas, and Rios (2013) also developed kinaesthetic learning applications using the Kinect sensor to help teaching math; they found that there is a relationship between body movements and learning processes. Sommool, Battulga, Shih, and Hwang (2013) tested the usability satisfaction of Kinect-enhanced "Holodeck" classroom; the results showed that the participants were satisfied with use of the system. More recently, Hsiao \& Chen (2016) used ASUS Xtion PRO, which is the Kinect-like device to test the effect of gesture interactive game-based learning (GIGL) on the learning performance and motor skills of pre-schoolers. The results of this study showed that GIGL system improved the kids' learning performance and their motor skills when compared to traditional activity game-based learning. Ke, Lee, and Xu (2016) also developed and examined the impact of Mixed-reality Integrated Learning Environment (MILE) on teaching performance; the Kinect-enabled sensorimotor interface was used to create a virtual reality learning method. MILE was used by 23 university teaching staff and they found that the MILE has reinforced the teaching tasks.

Although, the value and the benefits of the GBLS mode have been stated by several studies, a proper investigation of the influence of the GBLS mode on the learning outcomes is scarce. The previous studies lack the study of the impact on the GBLS mode of more than one category of learning outcome (cognitive, affective outcomes, etc.) at the same time. Moreover, none of these studies considered the differences in the students' characteristics such as learning styles and spatial ability levels. However, a comprehensive empirical research on the impact of the GBLS mode on learning outcomes is needed. Therefore, this study will be conducted to investigate the effectiveness of the GBLS on learning outcomes with guidance of models from TML field (Alavi \& Leidner, 2001; Piccoli, Ahmad, \& Ives, 2001).

\section{Research Framework}

The GBLS research field is still at its infancy stage, and up to the time of writing this paper (Sheu et al., 2013), there is no research model that is specially built to guide the GBLS research. Thus, Technology-Mediated Learning (TML) models will be used as a guide to achieve the objectives of this study. Alavi and Leidner (2001) and Piccoli et al. (2001) models were used to build the research framework. Below is a brief description of these two models.

Firstly, Alavi and Leidner's framework (2001). This framework provides a summary of the TML's literature. The framework outlines the potential research avenues in the TML field. It also illustrated and identified the missing dimensions of previous TML's research. Alavi and Leidner's framework was built based on input-process-output model and consists of four dimensions namely Instructional Strategy, Information Technology, Psychological Learning Processes, 
and Learning Outcomes. The framework mainly focuses on the relationship between the technology and the instructional strategy, and their effect on psychological learning processes, which influences the learning outcomes. Despite the value of Alavi and Leidner's framework, it ignores an important dimension, which is learner and instructor characteristics (Alavi \& Leidner, 2001; Wan \& Fang, 2006). According to Benbunan-Fich and Hiltz (2003) and Piccoli et al.(2001), learners' characteristics play important roles in the successes of the technology use in the learning field. Secondly, Piccoli et al.'s framework (2001) that was developed primarily for web-based learning. The framework adds the human dimension which is missing in the Alavi and Leidner's (2001) model. Piccoli's framework consists of only three dimensions: Human dimension, Design dimension, and Effectiveness dimension. However, Figure 2 shows the current research framework, the framework consists of three dimensions which are independent variables (three learning modes), dependent variables (learning outcomes) and moderating variables (learners' individual characteristics)

\section{Independent Variables: Learning Modes}

There are three learning modes used in this study as follows. More details will be described in Table 1 under Research Methodology section.

- Gesture Based Learning System (GBLS) mode

- Computer Simulation Software Learning (CSSL) mode

- Conventional Learning mode

\section{Dependent Variables: Learning Outcomes}

Learning outcomes cannot be measured directly, only the action and performance that result from learning can be measured (Alavi \& Leidner, 2001). Sharda et al. (2004) have categorised learning outcomes into three components: Cognitive Outcomes, Affective Outcomes, and Psychomotor Outcomes. Cognitive Outcomes include knowledge, comprehension, analysis, and application. Affective outcomes include learners' perception of satisfaction, attitude, and appreciation for learning experience using the new learning method. Psychomotor Outcomes includes response magnitude, accuracy, and efficacy. However, this research will measure the cognitive outcomes using pre-test and post-test grades, and the affective outcomes through the students' perception of learning effectiveness and satisfaction.

\section{Moderator Variable: Learners Characteristics}

Students are the most important participants in the education processes, and they represent the raw subjects for any educational system. Indeed, students are the key members of the stakeholders involved in the education cycle (Lengnick-Hall, 1996; Sirvanci, 1996). However, understanding students' characteristics is a crucial factor to ensure the success of an educational system or method. Individual differences of students include learning style, diversity in motivation, spatial abilities, and demographic differences (Alavi \& Leidner, 2001). According to Lengnick-Hall and Sanders (1997), the variation of students characteristics has become a challenge for all educational institutions around the world, as the individual differences may affect the learning outcomes of the students when they are taught by the same learning mode. Alavi and Leidner (2001) argue that studying the impact of any instructional based technology method on learning outcomes should be moderated by learning characteristics. This research focuses on investigating the influence of the GBLS mode on learning outcomes, therefore two learning characteristics will be studied as moderating variables (see Figure2), namely, learning styles and spatial abilities. 

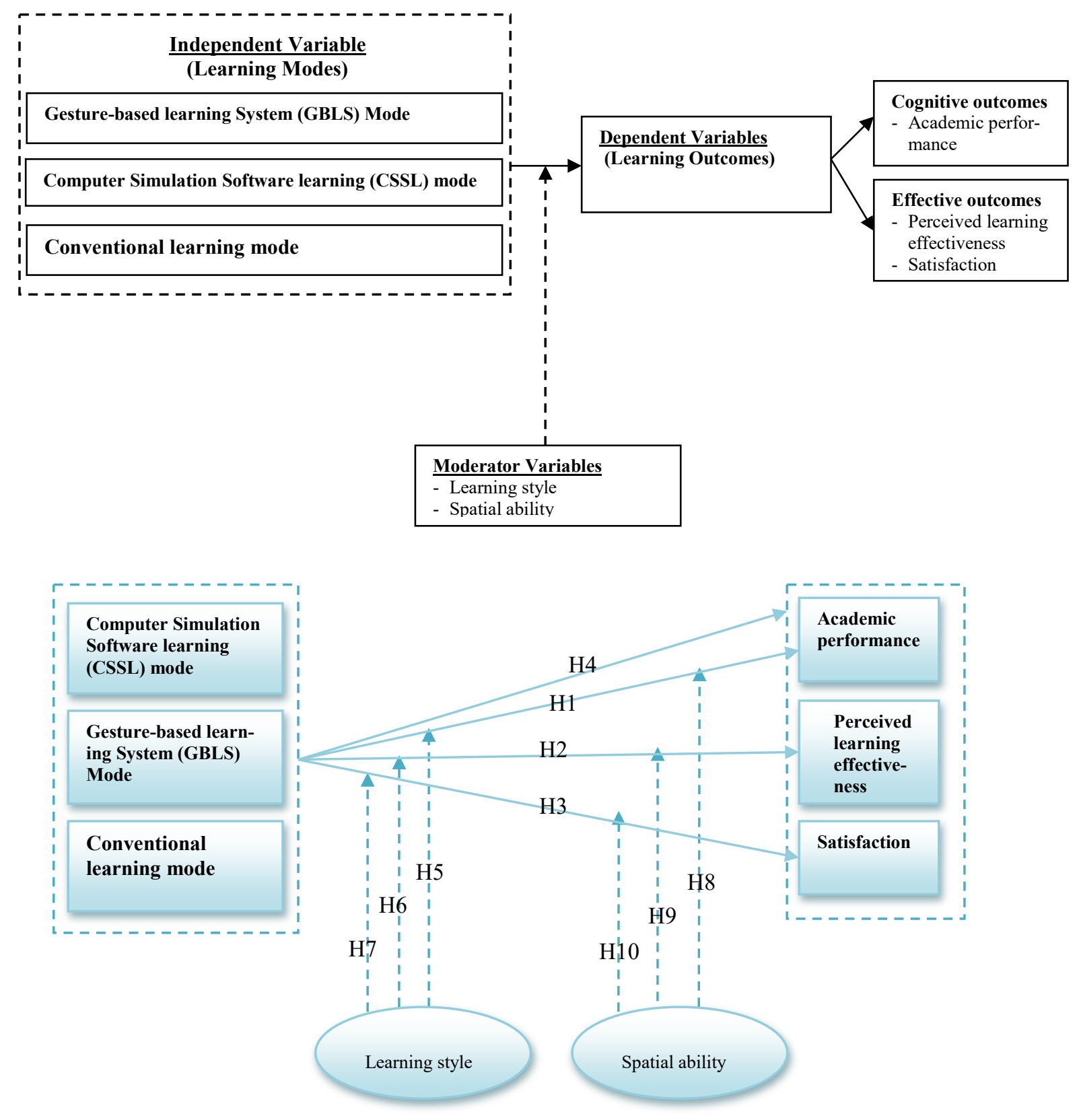

Figure 2: The research framework

\section{Research Methodology}

\section{Research Design and Procedures}

This research is explanatory quantitative research; a quasi-experimental research design has been used in this study in order to establish a causality relationship between the learning modes and learning outcomes. This study has been executed as follows. 
The Effectiveness of the Gesture-Based Learning System (GBLS)

\section{The Experiment Design and Tools}

The experiment consists of three groups, each group represent a specific learning mode (see Table 1):

Table 1: The experimental groups

\begin{tabular}{ll}
\hline Experimental group & Learning mode \\
\hline Group A & Gesture Based Learning system (GBLS) mode \\
\hline Group B & Computer Simulation Software Learning (CSSL) mode. \\
\hline Group C & Conventional learning mode \\
\hline
\end{tabular}

- Group A: The GBLS mode

This learning mode was set up by applying some modifications to a formal classroom, these modifications include the use of Microsoft Kinect sensor, which was connected to the classroom computer. OpenNI driver was installed the classroom PC in order for the Kinect sensor to work on the PC. K- Solar application was installed to the classroom PC. $\mathrm{K}$ - Solar system is Kinect based application. The application was developed by the Juan de Lanuza School and the BIFI- Biocomputation and Physics of Complex Systems Institute of the University of Zaragoza. The k-Solar System's developers have granted a license to the researcher to use it in this experiment.

- Group B: The CSSL mode This group was setup as follows. A computer lab was arranged prior to the experiment day. The Solar System 3D Simulator application was installed on the computers in the lab. The Solar System 3D was developed by Softonic International S.A Company and it is available to download for free on the company website.

- Group C: The conventional learning mode

Conventional classroom with computer and projector was used. PowerPoint presentation was prepared by the researcher to explain the topic.

\section{Participants}

A hundred and ninety-eight first-year undergraduate students voluntarily participated in the research from a total of about 500 first year undergraduate students at Almergib University (Mslatah city, Libya). Almergib University was chosen using convenience sampling method as the researcher had access to the university, which helped him to recruit students. Only first-year students were invited to participate to ensure consistency among participant's knowledge and experience. All participants are Libyan students. Out of 198 participants, only 151 participants completed all stages of the experiment with response rate of $76.2 \%$.

\section{Instruments to Measure Variables}

Most of the research instruments were adopted from previous studies and, some were added for the purpose of this study. Table 2 listed all the instruments used in this study. 
Table 2: Research instrument

\begin{tabular}{|c|c|c|c|c|}
\hline NO & Variable & $\begin{array}{l}\text { Type of } \\
\text { variable }\end{array}$ & Instrument & Source \\
\hline 1 & $\begin{array}{l}\text { Academic Per- } \\
\text { formance }\end{array}$ & Dependent & $\begin{array}{l}\text { Pre-test and post- } \\
\text { test }\end{array}$ & $\begin{array}{l}\text { Twenty-seven Multiple-Choice and } \\
\text { true/false Questions were Quoted from } \\
\text { test-bank, (Pearson Education, 2014), } \\
\text { and reviewed and edited by a profes- } \\
\text { sional lecturer in the subject area. }\end{array}$ \\
\hline 2 & $\begin{array}{l}\text { Perceived Learn- } \\
\text { ing Effectiveness }\end{array}$ & Dependent & Questionnaire & $\begin{array}{l}\text { Eleven items were adapted from pre- } \\
\text { vious studies (Benbunan-Fich \& Hiltz, } \\
\text { 2003; E. A. L. Lee, 2011; Marks, } \\
\text { Sibley, \& Arbaugh, 2005) }\end{array}$ \\
\hline 3 & Satisfaction & Dependent & Questionnaire & $\begin{array}{l}\text { Seven items were adopted from previ- } \\
\text { ous studies (Chou \& Liu, 2005; E. A. } \\
\text { L. Lee, 2011). }\end{array}$ \\
\hline 4 & Interactivity & Dependent & Questionnaire & $\begin{array}{l}\text { Three items were adopted from Pituch } \\
\text { and Lee (2006) }\end{array}$ \\
\hline 5 & Multimodality & Dependent & Questionnaire & $\begin{array}{l}\text { Three items were devolved from the } \\
\text { theory of multimodality. }\end{array}$ \\
\hline 6 & Learning style & Moderator & $\begin{array}{l}\text { Kolb Learning } \\
\text { Style Inventory } \\
\text { (LSI) }\end{array}$ & $\begin{array}{l}\text { Kolb Learning Style Inventory (LSI) } \\
\text { was used. (LSI) is commercially } \\
\text { available on: } \\
\text { (www.learningfromexperience.com). }\end{array}$ \\
\hline 7 & Spatial ability & Moderator & Spatial Ability Test & $\begin{array}{l}\text { The spatial ability test from Barrett } \\
\text { and Williams (2003) was used. }\end{array}$ \\
\hline
\end{tabular}

\section{Experimental Procedures:}

1. Participants were equally and randomly divided into three groups. $198 / 3=66$ participants are used in each group. Each group was randomly assigned to one of the three learning groups (See Table 3).

2. First session of the experiment: in this session all participants in the three groups were asked to sit for a pre-test and to complete the initial questionnaire. The initial questionnaire consists of three parts, which are background information, Kolb Learning Style Inventory, Spatial ability test.

3. Second session of the experiment: in this session;

a. Participants in Group (A) and Group (B) received 10 minutes introduction to the learning mode before lecture to ensure all participants are familiar with the use the technologies.

b. All Participants in the three different learning groups received a lecture using different modes based on the learning mode that they were assigned to (See Table 3). The learning topic title was Introduction to the solar system and time measurement. The lectures were delivered in the Arabic language (their native language) in the university. 
The Effectiveness of the Gesture-Based Learning System (GBLS)

Table 3: Assigning participants to the experimental groups

\begin{tabular}{cccc}
\hline Experimental group & Number of participants & Intervention & Lecture duration \\
\hline Group A & 66 & GBLS mode & 90 mins \\
\hline Group B & 66 & CSSL mode & 90 mins \\
\hline Group C & 66 & Conventional learning mode & 90 mins \\
\hline
\end{tabular}

4. After having received the treatment, all students in the three groups were asked to sit the post-test and complete the final questionnaire (See Figure 3). The final questionnaire consists of two parts: Perceived Learning Effectiveness, and Satisfaction.
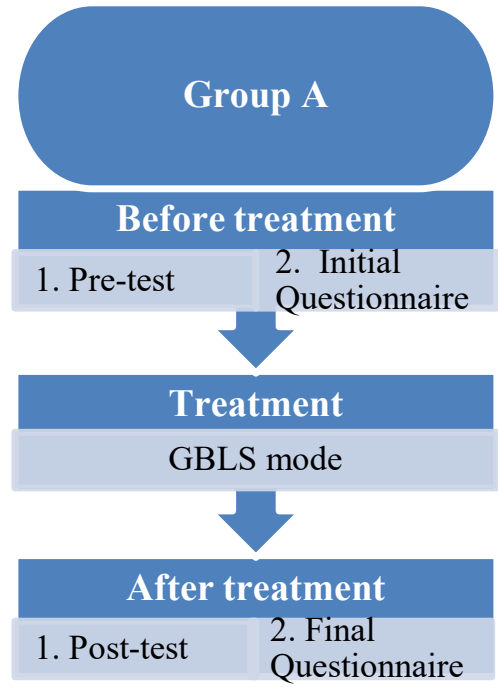
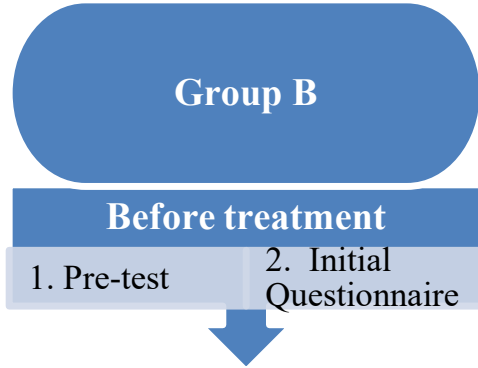

Treatment

CSSL mode

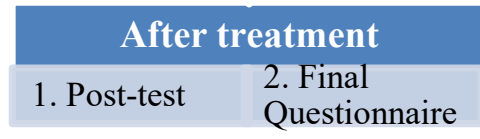

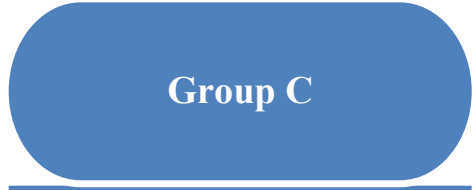

Before treatment

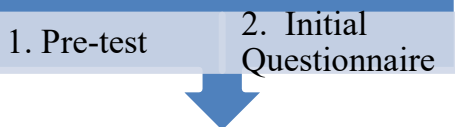

Treatment

Conventional Learning mode

After treatment

$\begin{array}{ll}\text { 1. Post-test } & \text { 2. Final } \\ \text { Questionnaire }\end{array}$

Figure 3: The Experiment Procedures

\section{Data Analysis}

Data were analysed using Statistical Package for Social Sciences (SPSS) Version 22. SPSS was used to run several statistical tests. First, descriptive statistics of the participants were investigated. Second, one-way Analysis of Covariance (ANCOVA) was conducted to determine the differences between the three groups in turn of the academic performance with pre-test as a covariate. Third, one-way analysis of variance (ANOVA) was carried up to determine whether there are any significant differences between the means of the three independent groups with respect to the perceived learning effectiveness and satisfaction. The one-way ANOVA was also used to explore any significant differences with respect to the academic performance, perceived learning effectiveness, and satisfaction between students with different learning styles and spatial abilities in the GBLS mode.

\section{Results}

This section presents the results of the data analysis; this section is divided into two sub-sections. The first sub-section presents a brief description of the subjects. The second sub-section presents the results of the hypnotised relationships. The significance level was set at 0.05 . A significance level of 0.05 implies that there is a $5 \%$ risk of claiming false difference. 


\section{Descriptive Statistics of the Participants}

A total of 151 participants completed all the stages of the experiment. The distribution of the participants in the groups, their gender, their age group and their courses are shown in Tables 4, 5 and 6 respectively.

Table 4: Gender Cross tabulation by Group

\begin{tabular}{llcrr}
\hline & & \multicolumn{2}{c}{ Gender } & Total \\
\cline { 2 - 4 } & & Male & Female & \\
\hline Group & Group A & 9 & 47 & 56 \\
\cline { 2 - 5 } & Group B & 29 & 11 & 40 \\
\cline { 2 - 5 } & Group C & 27 & 28 & 55 \\
\hline Total & & 65 & 86 & 151 \\
\hline
\end{tabular}

Table 5: Age Cross tabulation by Group

\begin{tabular}{lrrrrr}
\hline & & \multicolumn{3}{c}{ Age } & \multicolumn{2}{c}{ Total } \\
\cline { 2 - 5 } & & $(18-22)$ & $(23-26)$ & (over 26) & \\
\hline Group & Group A & 42 & 13 & 1 & 56 \\
\cline { 2 - 6 } & Group B & 38 & 1 & 1 & 40 \\
\cline { 2 - 6 } & Group C & 48 & 5 & 2 & 55 \\
\hline Total & 128 & 19 & 4 & 151 \\
\hline
\end{tabular}

Table 6: Area of study Cross tabulation by Group

\begin{tabular}{|c|c|c|c|c|c|c|c|c|c|c|c|}
\hline & & \multicolumn{9}{|c|}{ Area of study } & \multirow[t]{2}{*}{ Total } \\
\hline & & 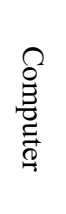 & 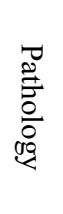 & : & 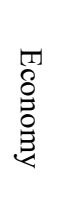 & $\begin{array}{c}3 \\
0 \\
0 \\
00 \\
00 \\
0 \\
0 \\
0 \\
0 \\
0\end{array}$ & 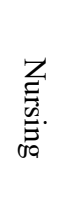 & 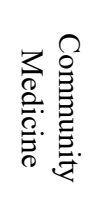 & 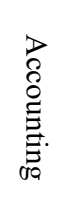 & 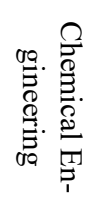 & \\
\hline \multirow[t]{3}{*}{ Group } & Group A & 23 & 15 & 8 & 0 & 6 & 3 & 1 & 0 & 0 & 56 \\
\hline & Group B & 0 & 0 & 0 & 33 & 4 & 0 & 0 & 3 & 0 & 40 \\
\hline & Group C & 12 & 2 & 25 & 0 & 8 & 0 & 6 & 0 & 2 & 55 \\
\hline Total & & 35 & 17 & 33 & 33 & 18 & 3 & 7 & 3 & 2 & 151 \\
\hline
\end{tabular}

\section{Hypotheses Examination}

This section presents the results of the hypotheses, the hypotheses are divided into two sets, and each set was developed to answer one research question as shown below.

\section{Q1: Does the GBLS mode influence the students' learning outcomes?}

In order to answer the first research question, 4 null hypotheses were developed. 
H1: There is no significant difference in the students' academic performance between the GBLS mode, CSSL mode, and conventional learning mode.

A one-way Analysis of Covariance (ANCOVA) was conducted to determine statistically significant differences between the GBLS, CSSL and conventional learning modes in the Post-test scores while controlling for Pre-test scores. There was no statistically significant difference between the learning mode in Post-test score after controlling for the pre-test scores, $F(2,147)=$ $2.19, p=.115$. Although, there were no statistically significant differences in the academic performance between the three groups, the researcher did find differences in the research sample. The students in the GBLS mode did better in post-test than the students in the other learning modes (see Figure 4).

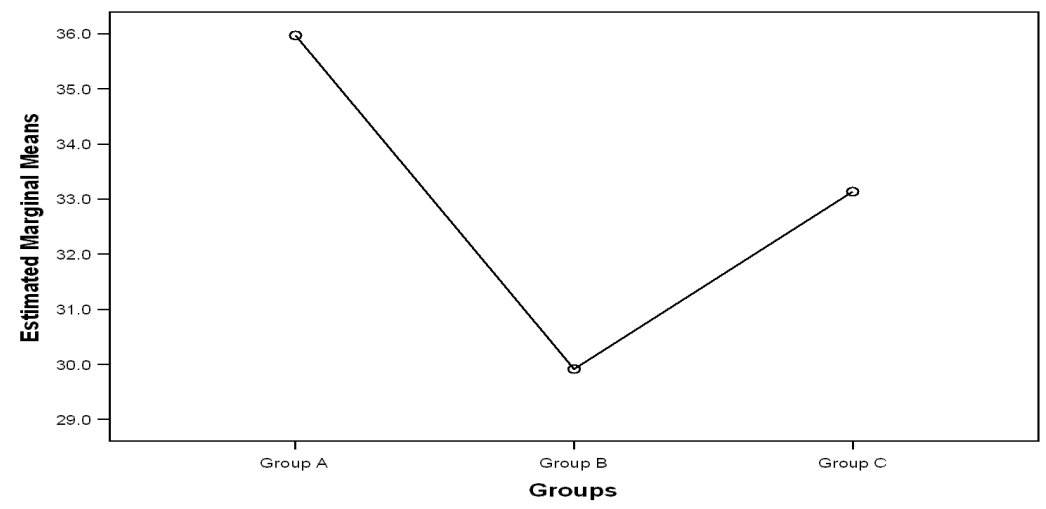

Figure 4: Estimated Margin means for Post Test Scores

$\mathrm{H} 2$ : There is no significant difference in the perceived learning effectiveness between the students in the GBLS mode, CSSL mode and conventional learning mode.

The one-way analysis of variance (ANOVA) was conducted to determine the difference in the Perceived Learning effectiveness between students in the three learning modes. A one-way ANOVA showed that the difference in perceived learning effectiveness between students in the group A (GBLS mode) $(\mathrm{N}=56, \mathrm{M}=81.52, \mathrm{SD}=9.95)$, the group $\mathrm{B}$ (CSSL mode) $(\mathrm{N}=40, \mathrm{M}=$ $70.4, \mathrm{SD}=16.60)$, and the group $\mathrm{C}$ (conventional learning mode) $(\mathrm{N}=55, \mathrm{M}=74.7, \mathrm{SD}=12.10)$ were statistically significant, $F(2,148)=9.44, p<.001$. The researcher needed to run a Welch and Brown-Forsythe test because the homogeneity of variance assumption was violated $p=.002$, however Welch and Brown-Forsythe test confirmed the one-way ANOVA results see (Table 7). As the one-way ANOVA results were statistically significant, Post Hoc analyses were conducted. Specifically, Games and Howell post hoc tests were conducted on all possible pairwise contrasts. Games and Howell tests were used because the homogeneity of variance assumption was violated, Games and Howell test adjusts for violations of the homogeneity of variance assumption. Games and Howell tests found the following pair of groups to be significantly different $(p<.05)$ : Group Aand Group B, $p=.001$, Group A and Group B, $p=.004$. The Games-Howell test also suggested that there is no significant difference between Group B and Group C, $p=.349$. In other words, students in the GBLS mode showed higher perceived learning effectiveness than other two groups B and C (See Figure 5).

Table 7: Robust Tests of Perceived Learning Effectiveness

\begin{tabular}{lcccc}
\hline & Statistic(a) & df1 & df2 & Sig. \\
\hline Welch & 9.676 & 2 & 85.065 & .000 \\
\hline Brown-Forsythe & 8.588 & 2 & 99.884 & .000 \\
\hline
\end{tabular}




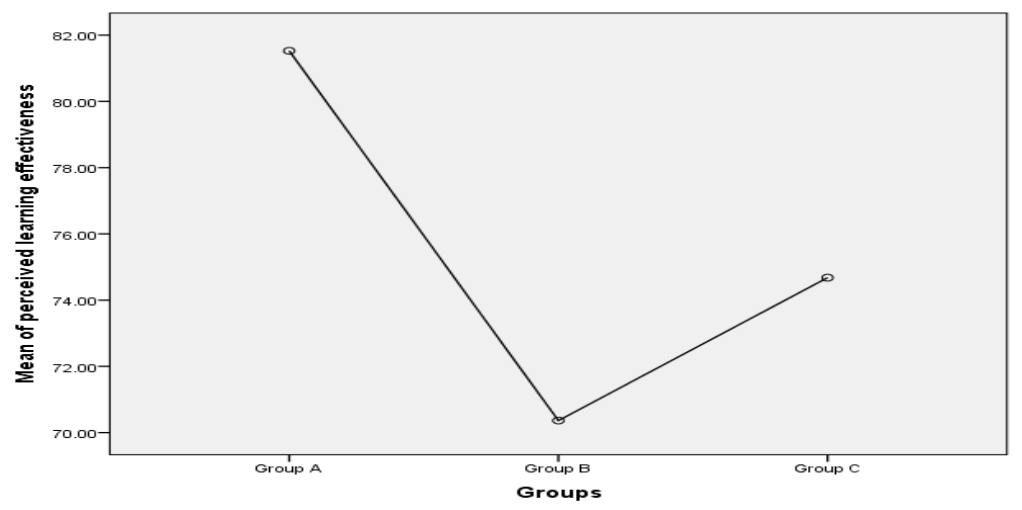

Figure 5: Estimated Margin means for perceived learning effectiveness

H3: There is no significant difference in the satisfaction between the students in the GBLS mode, CSSL mode and conventional learning mode.

The one-way analysis of variance (ANOVA) was conducted to determine the difference in the Satisfaction between students in the three learning modes. A one-way ANOVA showed that the difference in satisfaction between students in the group $\mathrm{A}(\mathrm{N}=56, \mathrm{M}=87.1, \mathrm{SD}=8.73)$, the group $\mathrm{B}(\mathrm{N}=40, \mathrm{M}=71.3, \mathrm{SD}=15.1)$, and the group $\mathrm{C}(\mathrm{N}=55, \mathrm{M}=65.3, \mathrm{SD}=15.90)$ were statistically significant, $(F(2,148)=38.1, p<.001)$. The researcher needed to run a Welch and Brown-Forsythe test because the homogeneity of variance assumption was violated $p=.001$. However, Welch and Brown-Forsythe tests confirmed the one-way ANOVA results see (Table 8). As the one-way ANOVA results were statistically significant, Post Hoc analyses were conducted. Specifically, Games and Howell post hoc tests were conducted on all possible pairwise contrasts. Games and Howell test found the following pair of groups to be significantly different: Group A and Group B $p<.001$, Group A and Group C, $p<.001$. The Games-Howell test also suggested that there is no significant difference between Group B and Group C, $p=.153$. In other word, students in the GBLS showed higher satisfaction than students in the other two groups B and C as shown in Figure 6.

Table 8: Robust Tests of Satisfaction

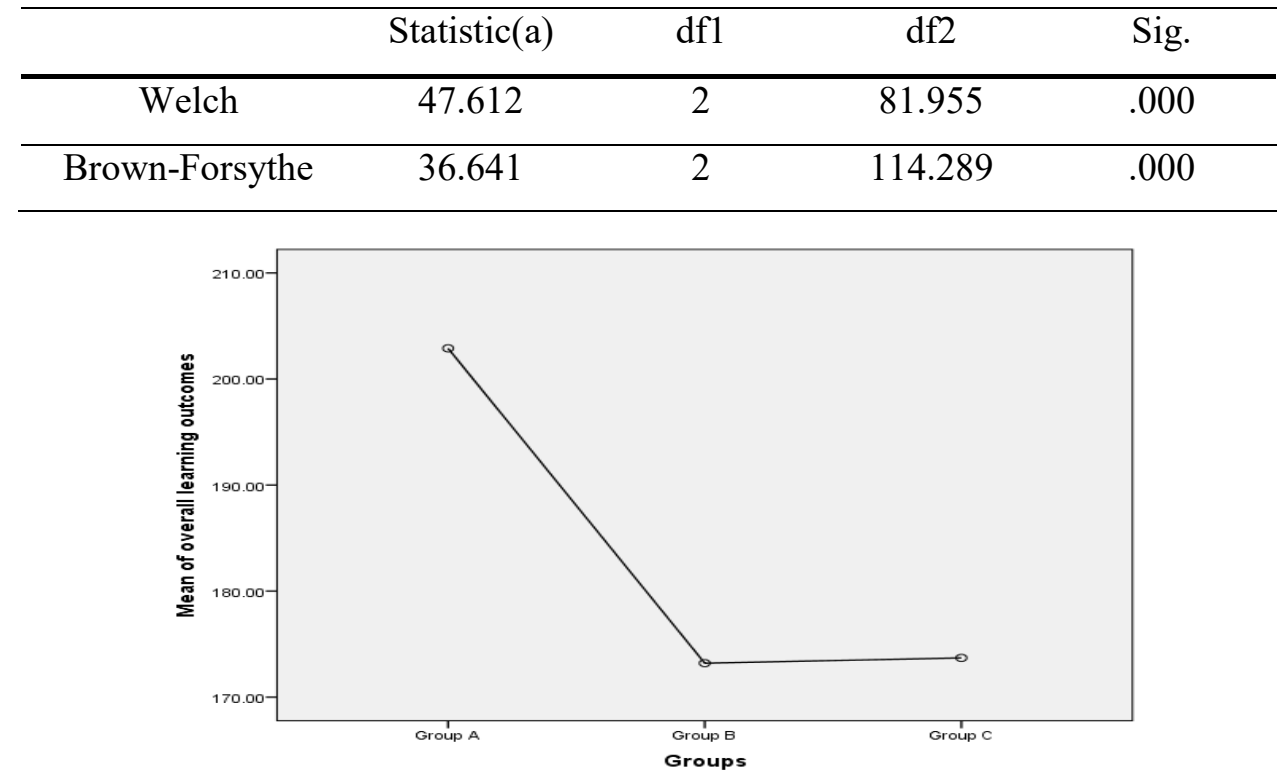

Figure 6: Estimated Margin means for satisfaction 
H4: There is no significant difference in the overall learning outcomes between the students in the GBLS mode, CSSL mode and conventional learning mode.

The one-way analysis of variance (ANOVA) was conducted to determine the difference in the overall learning outcomes between students in the three learning modes. A one-way ANOVA showed that the difference in overall learning outcomes between students in the group $A(N=56$, $\mathrm{M}=203, \mathrm{SD}=20.9)$, the group $\mathrm{B}(\mathrm{N}=40, \mathrm{M}=173, \mathrm{SD}=28.8)$, and the group $\mathrm{C}(\mathrm{N}=55, \mathrm{M}=$ $174, \mathrm{SD}=29.8)$ were statistically significant, $((F(2,148)=21.5, p<.001)$. As the one-way ANOVA results were statistically significant, Post Hoc analyses were conducted. Specifically, Tukey HSD post hoc test was conducted on all possible pairwise contrasts. Tukey HSD test found the following pair of groups to be significantly different: Group Aand Group B, $p<.001$, Group $\mathrm{A}$ and Group C, $p<.001$. The Games-Howell test also suggested that there is no statically significant difference between Group B and Group C, $p=.996$. Thus, students in the GBLS outperformed the students in the other two groups in overall learning outcomes (Figure 7).

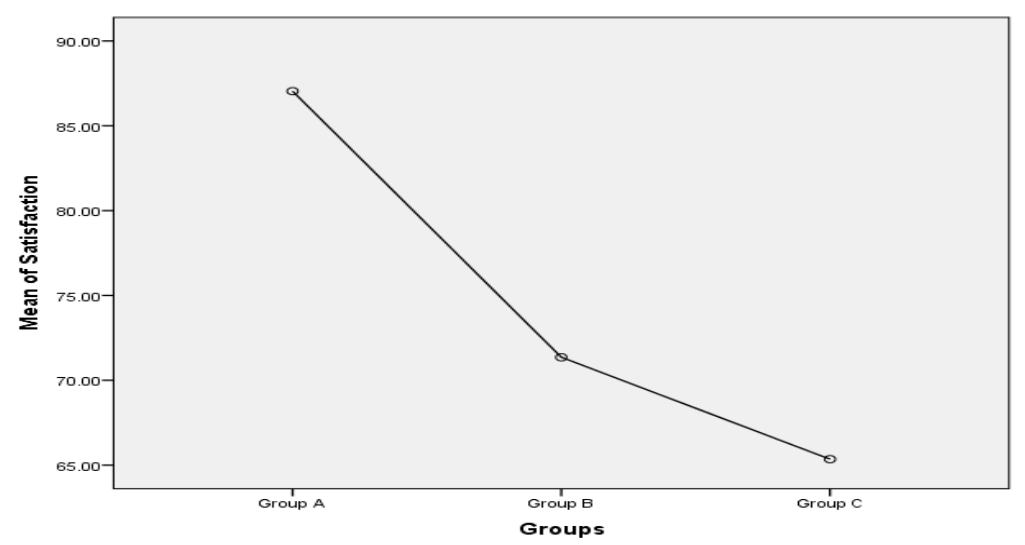

Figure 7: Estimated Margin means for overall learning outcomes

\section{Q2: Will the GBLS mode be able to accommodate all students with different learning styles and spatial abilities??}

In order to answer the second research question, 5 null hypotheses were developed.

H5: There is significant difference in the academic performance between students with different learning styles in the GBLS mode.

The one-way analysis of variance (ANOVA) was conducted to determine the difference in the Academic performance between the students with different learning style in the GBLS mode. One-way ANOVA showed that the difference in Academic Performance between the Diverging $(\mathrm{N}=16, \mathrm{M}=34.72, \mathrm{SD}=16.72)$, the Accommodating $(\mathrm{N}=10, \mathrm{M}=33.7, \mathrm{SD}=11.6)$, the Assimilating $(\mathrm{N}=16, \mathrm{M}=33.1, \mathrm{SD}=14.1)$, and the Converging $(\mathrm{N}=14, \mathrm{M}=35.7, \mathrm{SD}=13.9)$ were not statistically significant, $(F(3,52)=.091, p=.965)$. Therefore, there was no significant difference in the academic achievement between students with different learning styles in the GBLS mode.

H6: There is a significant difference in the perceived learning effectiveness between students with different learning styles in the GBLS mode.

The one-way analysis of variance (ANOVA) was conducted to determine the difference in the perceived learning effectiveness between the students with different learning style in the GBLS mode. A one-way ANOVA showed that the difference in the perceived learning effectiveness 
between the Diverging $(\mathrm{N}=16, \mathrm{M}=82.50, \mathrm{SD}=6.99)$, the Accommodating $(\mathrm{N}=10, \mathrm{M}=83.63$, $\mathrm{SD}=6.96)$, the Assimilating $(\mathrm{N}=16, \mathrm{M}=81.8, \mathrm{SD}=12.6)$, and the Converging $(\mathrm{N}=14, \mathrm{M}=$ $78.6, \mathrm{SD}=11.5)$ learning styles were not statistically significant, $(F(3,52)=.603, p=.616)$. The researcher needed to run Welch and Brown-Forsythe tests because the homogeneity of variance assumption was violated $p=.044$.However, Welch and Brown-Forsythe tests confirmed the oneway ANOVA results see (Table 9). Therefore, there was no significant difference in the perceived learning effectiveness between students with different learning styles in the GBLS mode.

Table 9: Robust Tests of Perceived learning effectiveness

\begin{tabular}{ccccc}
\hline & Statistic(a) & df1 & df2 & Sig. \\
\hline Welch & .595 & 3 & 27.058 & .624 \\
\hline Brown-Forsythe & .638 & 3 & 44.117 & .594 \\
\hline
\end{tabular}

H7: There is a significant difference in the satisfaction between students with different learning styles in the GBLS mode.

The one-way analysis of variance (ANOVA) was conducted to determine the difference in satisfaction between the students with different learning styles in the GBLS mode. A one-way ANOVA showed that the difference in Satisfaction between Diverging $(\mathrm{N}=16, \mathrm{M}=81.3, \mathrm{SD}=$ 1.60), the Accommodating $(\mathrm{N}=10, \mathrm{M}=80.85, \mathrm{SD}=6.64)$, the Assimilating $(\mathrm{N}=16, \mathrm{M}=80.7$, $\mathrm{SD}=1.39)$, and the Converging $(\mathrm{N}=14, \mathrm{M}=78.4, \mathrm{SD}=10.8)$ learning styles were not statistically significant, $(F(3,52)=.423, p=.737)$. Therefore, there was no significant difference in satisfaction between students with different learning styles in the GBLS mode.

H8: There is a significant difference in the Academic performance between students with different spatial ability levels in the GBLS.

The one-way analysis of variance (ANOVA) was conducted to determine the difference in the Academic performance between the students with different spatial ability levels in the GBLS mode. One-way ANOVA showed that the difference in the academic performance between students in the High $(\mathrm{N}=23, \mathrm{M}=36.1, \mathrm{SD}=13.3)$, the Medium $(\mathrm{N}=21, \mathrm{M}=35.5, \mathrm{SD}=16.4)$, and the low $(\mathrm{N}=12, \mathrm{M}=29.01, \mathrm{SD}=10.5)$ levels of spatial ability were not statistically significant, $(F(2,52)=1.096, p=.342)$.

H9: There is a significant difference in the perceived learning effectiveness between students with different spatial ability levels in the GBLS.

The one-way analysis of variance (ANOVA) was conducted to determine the difference in the perceived learning effectiveness between the students with different spatial ability levels in the GBLS mode. A one-way ANOVA showed that the difference in the perceived learning effectiveness between the High $(\mathrm{N}=23, \mathrm{M}=80.3, \mathrm{SD}=11.1)$, the Medium $(\mathrm{N}=21, \mathrm{M}=81.6$, $\mathrm{SD}=7.58)$, and the Low $(\mathrm{N}=12, \mathrm{M}=83.6, \mathrm{SD}=9.95)$ levels of spatial ability were not statistically significant, $(F(2,53)=.432, p=.652)$.

H10: There is a significant difference in the satisfaction between students with different spatial ability levels in the GBLS

The one-way analysis of variance (ANOVA) was conducted to determine the difference in the satisfaction between the students with different spatial ability levels in the GBLS mode. A oneway ANOVA showed that the difference in the satisfaction between the High $(\mathrm{N}=23, \mathrm{M}=$ $85.59, \mathrm{SD}=9.86)$, the Medium $(\mathrm{N}=21, \mathrm{M}=88.9, \mathrm{SD}=6.34)$, and the Low $(\mathrm{N}=12, \mathrm{M}=87.1$, $\mathrm{SD}=1.16)$ levels of spatial ability were not statistically significant, $(F(2,53)=.860, p=.429)$. The researcher needed to run Welch and Brown-Forsythe tests because the homogeneity of vari- 
ance assumption was violated $p<.05$, however, Welch and Brown-Forsythe tests confirmed the one-way ANOVA results (see Table 10). Therefore, there was no significant difference in the satisfaction between students with different learning styles in the GBLS mode.

Table 10: Robust Tests of Satisfaction

\begin{tabular}{ccccc}
\hline & Statistic(a) & df1 & df2 & Sig. \\
\hline Welch & 1.036 & 2 & 26.332 & .369 \\
\hline Brown-Forsythe & .796 & 2 & 33.023 & .460 \\
\hline
\end{tabular}

\section{Discussions and Conclusions}

This study was conducted to investigate the effectiveness of the GBLS mode. The main purpose of the research, that is, to investigate the effectiveness of the GBLS mode, was broken down into more specific questions as follows. First, does the GBLS influence students' learning outcomes? Second, will the GBLS mode be able to accommodate all students with different learning styles and spatial abilities? Those two questions were addressed in this paper. In order to answer the research questions, a quasi-experiment was used to compare the learning outcomes of the GBLS mode, CSSL mode, and conventional learning mode.

The current research yielded additional evidence that the GBLS mode can positively influence the learning outcomes of students. Students in the GBLS mode achieved higher scores in overall learning outcomes than the students in the other two learning modes. In addition, the current research results showed that students in the GBLS mode outperformed students in the other learning groups at perceived learning effectiveness and satisfaction (Affective outcomes). On the other hand, the current research found that there is no statistically significant difference in the academic performance (cognitive outcomes) between students in the GBLS, the CSSL, and the conventional learning modes. Although, there were no statistically significant differences in the academic performance between the three groups, the researcher did find differences in the research sample. The students in the GBLS did better in the post-test than the students in the other learning modes. The results of better academic achievement were consistent with the result that obtained by Chang et al. (2013) and Chao et al. (2013). This improvement of the students' academic performance could be explained by the Embodied Cognition theory, which is a cognitive science theory that believes that there is a connection of cognitive tasks with the physical environment in supporting concept understanding and learning for most students (Chao et al., 2013).

The results of a higher level of perceived learning effectiveness indicated that students believed the GBLS mode can help them to achieve a better understanding of the learning content, to summarise the main ideas of the topic, and to be more confident to express and discuss their ideas. These results showed that the GBLS mode made the students more interested in the learning and they wanted to learn more. These results could be explained through the interactivity that is one of the main features of the GBLS mode. It has been proved that interactive learning experience improves student skills such as problem-solving and critical thinking (Saye \& Brush, 2001). Similarly, the results of a high level of satisfaction indicated that students enjoyed the GBLS mode experience, and they were satisfied with the learning environment and the learning instructions. These results matched the results that were reported by Sommool et al. (2013).

The second part of the research investigation showed the GBLS mode was able to accommodate all learners with different learning styles and spatial ability levels. These results met the requirement of effective learning systems that have been stated by Lengnick-Hall and Sanders (1997); they stated that the effective education system should be able to accommodate all students with different individual characteristics in order to obtain consistent learning outcomes. Lage, Platt, 
and Treglia (2000) emphasised that the failure to match the teacher's instructing style and a pupil's learning style can make the student less interested in the learning experience. From the research results, it could be concluded that the GBLS mode provided an inclusive classroom environment that fulfils the needs of all learners with different characteristics. These results can be explained by the multimodality, which represents one of the main features of the GBLS mode as explained in the literature review section.

To sum up, at the beginning of this article, the authors mentioned that a proper investigation of the effectiveness of the GBLS mode is needed. The literature of the knowledge area supported the research argument as it revealed that the research in the GBLS field is still in its infancy stages. However, this study offered an experimental investigation of the effectiveness of the GBLS mode with the guidance of some Technology Mediated Learning (TML)'s models. The findings of this study suggested that the learning outcomes of the GBLS mode outperformed the other two learning modes: the CSSL mode and conventional learning mode. In addition, the results of this research also recommend that the GBLS mode is able to serve all learners with various individual characteristics. The outcomes of this study are important because they provide additional scientific evidence of the value of GBLS. It would be fruitful to pursue further research about how the GBLS mode influences the learning outcomes.

\section{References}

Abrahamson, D., Gutiérrez, J., Charoenying, T., Negrete, A., \& Bumbacher, E. (2012). Fostering hooks and shifts: Tutorial tactics for guided mathematical discovery. Technology, Knowledge and Learning, 17(12), 61-86. doi: 10.1007/s10758-012-9192-7

Alavi, M., \& Leidner, D. E. (2001). Research commentary: Technology-mediated learning-A call for greater depth and breadth of research. Information Systems Research, 12(1), 1. doi: 10.1287/isre.12.1.1.9720

Ayala, N. A. R., Mendívil, E. G., Salinas, P., \& Rios, H. (2013). Kinesthetic learning applied to mathematics using kinect. Procedia Computer Science, 25, 131-135.

Barrett, J., \& Williams, G. (2003). Test your own aptitude. Kogan Page Publishers.

Benbunan-Fich, R., \& Hiltz, S. R. (2003). Mediators of the effectiveness of online courses. Professional Communication, IEEE Transactions on, 46(4), 298-312.

Chang, C.-Y., Chien, Y.-T., Chiang, C.-Y., Lin, M.-C., \& Lai, H.-C. (2013). Embodying gesture-based multimedia to improve learning. British Journal of Educational Technology, 44(1), E5-E9. doi: 10.1111/j.1467-8535.2012.01311.x

Chao, K.-J., Huang, H.-W., Fang, W.-C., \& Chen, N.-S. (2013). Embodied play to learn: Exploring Kinectfacilitated memory performance. British Journal of Educational Technology, 44(5), E151-E155. doi: $10.1111 /$ bjet. 12018

Chou, S.-W., \& Liu, C.-H. (2005). Learning effectiveness in a Web-based virtual learning environment: A learner control perspective. Journal of Computer Assisted Learning, 21(1), 65-76. doi: 10.1111/j.13652729.2005.00114.x

Cuban, L. (1986). Teachers and machines: The classroom use of technology since 1920: Teachers College Press.

Di Tore, S. (2012). Didactics, movement and technology: New frontiers of the human-machine interaction. Journal of Human Sport and Exercise, 7(1 proc), S178-S184. doi: 10.4100/jhse.2012.7.Proc1.20

Evans, M. (2012). Gestural interfaces in learning. Paper presented at the Society for Information Technology \& Teacher Education International Conference.

Gage, R. (1995). Excuse me, you're cramping my style: Kinesthetics for the classroom. English Journal, $84(8), 52-55$. 
The Effectiveness of the Gesture-Based Learning System (GBLS)

Hsiao, H.-S., \& Chen, J.-C. (2016). Using a gesture interactive game-based learning approach to improve preschool children's learning performance and motor skills. Computers \& Education, 95, 151-162. doi: http://dx.doi.org/10.1016/j.compedu.2016.01.005

Hsu, H.-M. J. (2011a). The potential of Kinect as interactive educational techonology. Paper presented at the 2nd International Conference on Education and Management Technology, Singapur.

Hsu, H.-M. J. (2011b). The potential of kinect in education. International Journal of Information and Education Technology, 1(5), 365.

John, P., \& Sutherland, R. (2005). Affordance, opportunity and the pedagogical implications of ICT. Educational Review, 57(4), 405-413. doi: 10.1080/00131910500278256

Johnson, L., Adams Becker, S., Witchey, H., Cummins, M., Estrada, V., Freeman, A., \& Ludgate, H. (2011). The NMC Horizon Report: 2011 museum edition. Austin, Texas: The New Media Consortium.

Johnson, L., Adams Becker, S., Witchey, H., Cummins, M., Estrada, V., Freeman, A., \& Ludgate, H. (2012). The NMC Horizon Report: 2012 museum edition. Austin, Texas: The New Media Consortium.

Kam, L., Konrad, J., \& Ishwar, P. (2012, 22-24 April 2012). A gesture-driven computer interface using Kinect. Paper presented at the Image Analysis and Interpretation (SSIAI), 2012 IEEE Southwest Symposium on.

Kandroudi, M., \& Bratitsis, T. (2012). Exploring the educational perspectives of XBOX Kinect based video games. Proceedings of the 6th European Conference on Games Based Learning, 219-227.

$\mathrm{Ke}, \mathrm{F}$., Lee, S., \& Xu, X. (2016). Teaching training in a mixed-reality integrated learning environment. Computers in Human Behavior, 62, 212-220. doi: http://dx.doi.org/10.1016/j.chb.2016.03.094

Kirsh, D. (2013). Embodied cognition and the magical future of interaction design. ACM Transactions on Computer-Human Interaction (TOCHI), 20(1), 3.

Lage, M. J., Platt, G. J., \& Treglia, M. (2000). Inverting the classroom: A gateway to creating an inclusive learning environment. The Journal of Economic Education, 31(1), 30-43.

Lang, S., Block-Berlitz, M., \& Rojas, R. (2011). Sign language recognition with Kinect. Bachelor, Institut für Informatik, Freie Universitä $t$ Berlin.

Lee, E. A. L. (2011). An investigation into the effectiveness of virtual reality-based learning. Murdoch University.

Lee, W.-J., Huang, C.-W., Wu, C.-J., Huang, S.-T., \& Chen, G.-D. (2012). The effects of using embodied interactions to improve learning performance. Paper presented at the Advanced Learning Technologies (ICALT), 2012 IEEE 12th International Conference on.

Lengnick-Hall, C. A. (1996). Customer contributions to quality: A different view of the customer-oriented firm. Academy of Management Review, 21(3), 791-824.

Lengnick-Hall, C. A., \& Sanders, M. M. (1997). Designing effective learning systems for management education: Student roles, requisite variety, and practicing what we teach. Academy of Management Journal, 40(6), 1334-1368.

Marks, R. B., Sibley, S. D., \& Arbaugh, J. B. (2005). A structural equation model of predictors for effective online learning. Journal of Management Education, 29(4), 531-563.

Meng, M., Fallavollita, P., Blum, T., Eck, U., Sandor, C., Weidert, S., . . Navab, N. (2013). Kinect for interactive AR anatomy learning. Paper presented at the Mixed and Augmented Reality (ISMAR), 2013 IEEE International Symposium on.

O’Hanlon, C. (2007). Gaming: Eat breakfast, drink milk, play Xbox. T.H.E. Journal, 34(4), 34-39.

O’Donovan, C., Hirsch, E., Holohan, E., McBride, I., McManus, R., \& Hussey, J. (2012). Energy expended playing Xbox Kinect ${ }^{\mathrm{TM}}$ and $\mathrm{Wii}$ TM games: A preliminary study comparing single and multiplayer modes. Physiotherapy, 98(3), 224-229. doi: http://dx.doi.org/10.1016/j.physio.2012.05.010 
Oviatt, S., \& Wahlster, W. (1997). Introduction to this special issue on multimodal interfaces. HumanComputer Interaction, 12(1-2), 1-5.

Pearson Education. (2014). Celestial timekeeping and navigation.

Piccoli, G., Ahmad, R., \& Ives, B. (2001). Web-based virtual learning environments: A research framework and a preliminary assessment of effectiveness in basic IT skills training. MIS Quarterly, 25(4), 401426.

Pituch, K. A., \& Lee, Y.-k. (2006). The influence of system characteristics on e-learning use. Computers \& Education, 47(2), 222-244.

Ratner, H. H., Foley, M. A., \& McCaskill, P. (2001). Understanding children's activity memory: The role of outcomes. Journal of Experimental Child Psychology, 79(2), 162-191.

Saye, J., \& Brush, T. (2001). The use of embedded scaffolds with hypermedia-supported student-centered learning. Journal of Educational Multimedia and Hypermedia, 10(4), 333-356.

Sharda, R., Romano, N. C., Jr., Lucca, J. A., Weiser, M., Scheets, G., Chung, J.-M., \& Sleezer, C. M. (2004). Foundation for the study of computer-supported collaborative learning requiring immersive presence. Journal of Management Information Systems, 20(4), 31-64.

Sheu, F.-R., \& Chen, N.-S. (2014). Taking a signal: A review of gesture-based computing research in education. Computers \& Education, 78, 268-277. doi: 10.1016/j.compedu.2014.06.008

Sheu, F.-R., Fang, W.-C., \& Chen, N.-S. $(2013,2013)$. How gesture-based technology is used in education to support teaching and learning: A content analysis.

Shih-Ching, Y., Wu-Yuin, H., Tzu-Chuan, H., Wen-Kang, L., Yu-Tsung, C., \& Yen-Po, H. (2012). A study for the application of body sensing in assisted rehabilitation training. Paper presented at the Computer, Consumer and Control (IS3C), 2012 International Symposium on.

Sirvanci, M. (1996). Are students the true customers of higher education? Quality Progress, 29(10), 99.

Sommool, W., Battulga, B., Shih, T. K., \& Hwang, W.-Y. (2013). Using Kinect for holodeck classroom: A framework for presentation and assessment. Advances in Web-Based Learning-ICWL 2013 (pp. 4049): Springer.

Stevanoni, E., \& Salmon, K. (2005). Giving memory a hand: Instructing children to gesture enhances their event recall. Journal of Nonverbal Behavior, 29(4), 217-233.

Turk, M. (2001). Perceptual user interfaces. In R. Earnshaw, R. Guedj, A. Van Dam, \& J. Vince (Eds.), Frontiers of human-centered computing, online communities and virtual environments (pp. 39-51): Springer.

Turk, M., \& Robertson, G. (2000). Perceptual user interfaces (introduction). Communnications of the ACM, 43(3), 32-34. doi: 10.1145/330534.330535

Villaroman, N., Rowe, D., \& Swan, B. (2011). Teaching natural user interaction using OpenNI and the Microsoft Kinect sensor. Paper presented at the Proceedings of the 2011 conference on Information Technology Education.

Wan, Z., \& Fang, Y. (2006). The role of information technology in technology-mediated learning: A review of the past for the future. AMCIS 2006 Proceedings, 253.

Watson, D. (2001). Pedagogy before technology: Re-thinking the relationship between ICT and teaching. Education and Information Technologies, 6(4), 251-266. doi: 10.1023/A:1012976702296

Zhang, Z. (2012). Microsoft kinect sensor and its effect. MultiMedia, IEEE, 19(2), 4-10. 


\section{Biographies}

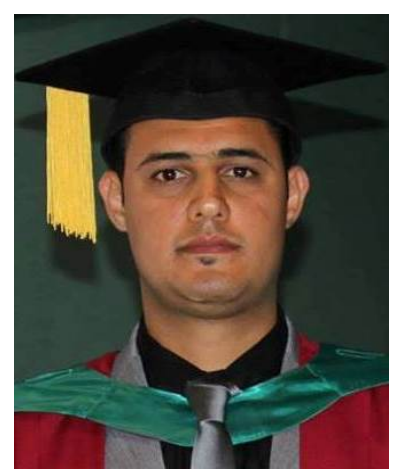

Moamer Ali Ahmed Shakroum is currently a DIT student in the School of Engineering and Information Technology at Murdoch University, South Street Campus, Western Australia. He completed his Master of Science in IT (Internetworking and security specialisation) in 2013 at Murdoch University. He held his bachelor's degree in computer science from Almergib University, Libya in 2007. Prior to his DIT candidature, he was a full-time teaching assistant and computer Labs supervisor at Almergib University in Libya. His research interests include eLearning, learning technologies and human-computer interaction.

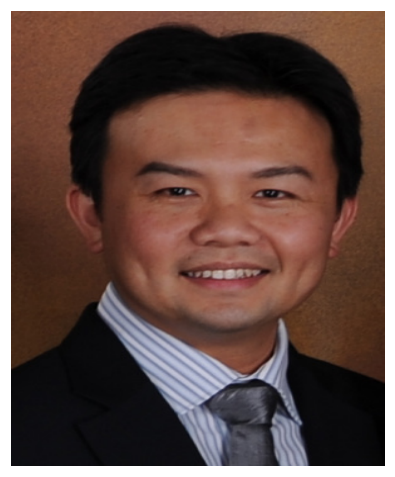

Kok Wai Wong is currently working as an associate professor with the School of Engineering and Information Technology at Murdoch University in Western Australia. He is the current the chapter chair for IEEE Systems, Man, and Cybernetics Society (WA Chapter). He is also serving as a member for the Emergent Technologies Technical Committee (ETTC) and Game Technical Committee (GTC) of the IEEE Computational Intelligence Society (CIS). He involved in the editorial boards for a number of international journals and in many international conference organising committees. He is the general conference co-chair for the 7th International Conference on e-Learning and Games, the 24th Australasian Joint Conference on Artificial Intelligence, the Second International Conference on Digital Interactive Media in Entertainment and Arts, and the Joint International Conference on Cyber Games and Interactive Entertainment. $\mathrm{He}$ is the program co-chair for the 21 st International Conference on Neural Information Processing (ICONIP 2014). His current research interests include intelligent data analysis, computational intelligence, human-computer interfaces and games technology.

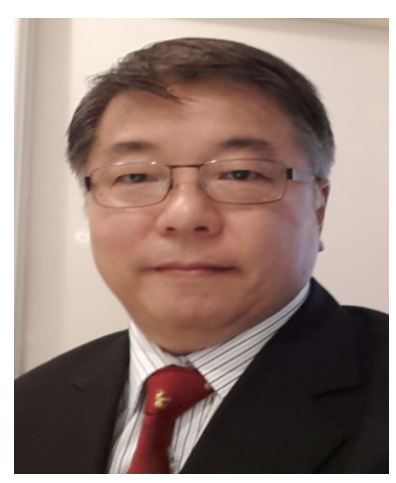

Lance Chun Che Fung commenced his service at Murdoch University on February 2003. He was appointed as Emeritus Professor in the School of Engineering and Information Technology since October 2015. Lance was trained as a Radio and Electronic Officer in the merchant navy during the 70 's. He then graduated with a B.Sc. Degree with First Class Honours in Maritime Studies and a Master of Engineering Degree in System Test Technology, from the University of Wales, United Kingdom in the early 80's. He taught at the Department of Electronics and Communication Engineering, Singapore Polytechnic (1982-1988), and at the School of Electrical and Computer Engineering, Curtin University of Technology (1989-2003). His research interest is in the development and applications of innovative technologies and advanced techniques to solve practical problems. Professor Fung has published over 300 articles in refereed journals and conference proceedings. 